\title{
EL ARCHIVO COMO RETROSPECTIVA ALDO SESSA 1958-2018
}

\author{
THE ARCHIVE AS RETROSPECTIVE \\ ALDO SESSA 1958-2018
}

Victoria Macioci | victoriamacioci@hotmail.com

Facultad de Bellas Artes. Universidad Nacional de La Plata. Argentina

Recibido: 20/3/2018 | Aceptado: 8/7/2018

\section{RESUMEN}

En este texto se pone de relieve la función fundamental del archivo de artista para la realización y la organización de una exposición retrospectiva que exhiba su producción y trayectoria. Se utilizará como estudio de caso la muestra Archivo Aldo Sesso 1958-2018: 60 oños de fotografías, con curaduría de Victoria Noorthoon. La misma fue realizada entre el 21 de marzo y el 27 de mayo de 2018 en el Museo de Arte Moderno de Buenos Aires (MAMBA).

\section{PALABRAS CLAVE}

Archivo; retrospectiva; fotografía; Aldo Sessa

\section{ABSTRACT}

In this text it is highlighted the main role of the artist archive for the realization and organization of a retrospective exhibition that exposes his path is highlighted. The work used as a case study is the exhibition Archivo Aldo Sesso 1958-2018: 60 años de fotografías, curated by Victoria Noorthoon. It was held between March 21 and May 272018 at the Museum of Modern Art in Buenos Aires (MAMBA).

\section{KEYWORDS}

Archive; retrospective; photography; Aldo Sessa 
La muestra Archivo Aldo Sessa 1958-2018: 60 años de fotografías, realizada en el Museo de Arte Moderno de Buenos Aires (MAMBA), es ejemplo del nuevo lugar que ocupa el archivo en el arte contemporáneo debido a que, en los últimos años, la noción de este ha sido teorizada por la Historia del Arte y se expandió el uso que los artistas hacen del mismo. En la actualidad, por ejemplo, artistas reconocidos de nuestro país donan o venden sus archivos personales a importantes instituciones museísticas como material valioso para la activación y construcción de diversos relatos del arte latinoamericano.

Es así que esta temática se han vuelto tema de investigación teórica en el campo del arte y, como es el caso del ejemplo planteado, se han organizado muestras retrospectivas que tienen el archivo del artista como matriz fundamental con igual legitimación que el de una investigación teórica, sus críticas artísticas o hasta la curaduría de las exhibiciones realizadas por él.

Ahora bien, ¿cómo se concibe el archivo desde el arte? Las investigaciones del campo artístico sobre el mismo abarcan un recorrido teórico que va desde los postulados de Michael Foucault (1979), quien lo define como «el sistema que rige la aparición de los enunciados como acontecimientos singulares» (p. 219) hasta la disciplina archivística más técnica y concreta que lo considera el conjunto de documentos que guarda una institución. Dentro del campo esta noción, según Ana María Guasch (2011), puede ser aplicada tanto a modalidades particulares de producción artística como a obras que se presentan a sí mismas como archivos:

\footnotetext{
Las distintas prácticas del archivo suponen no sólo reescribir una historia descentrada

a partir de un entrecruzamiento de distintos marcos sociales, sino plantear una reorientación radical en la representación y experiencia del espacio y del tiempo que implique una nueva lógica de la representación cultural, una determinación de la memoria cultural que se desligue de la historia como progresión lineal y finalista, y una superación del propio archivo como origen tipológico y registro del tiempo contingente, es decir, del archivo «de procedencia» del siglo XIX (p. 46).
}

En la práctica cotidiana de trabajo los artistas elaboran, consciente o inconscientemente, archivos, entre los cuales se distinguen aquellos de carácter documental profesional, tal vez no relacionados directamente con la producción de sus obras, y los acervos que se conforman específicamente a partir de las necesidades generadas para la realización de determinados proyectos artísticos.

En este sentido, fue Hal Foster (2016) uno de los primeros críticos en sostener que la conexión entre arte y archivo puede traducirse como una tendencia de la escena actual, en donde el artista deviene archivista. Con mayor precisión, Foster plantea que, en realidad, no se trata solamente de un vínculo entre dos dimensiones 
diferentes, sino, más bien, de un impulso de archivo que subyace al propio trabajo artístico. Esta es la materia prima de las manifestaciones artísticas que se pueden considerar arte de archivo.

A partir de entender la configuración del archivo personal como una construcción biográfica en la que se condensan memoria e identidad, es dificultoso transpolar estas características a las categorías más generales de la producción artística; por lo tanto, se presenta la necesidad de continuar ampliando los horizontes teóricos sobre los acervos privados de artistas que carecen de organización lineal y de políticas estructuradas de archivamiento. A través de la teorización en este sentido, se podrá realizar un análisis más enriquecedor sobre lo que dicen y callan este tipo de archivos.

\section{EL ARCHIVO EXPUESTO}

Para el caso propuesto, Victoria Noorthoorn, directora del MAMBA, emprendió la tarea de trabajar sobre el prolífico archivo de Aldo Sessa ${ }^{1}$ como curadora de esta exhibición. En estos sesenta años, su acervo se amplió a unas 800000 imágenes en planchas de contactos, negativos, copias impresas o digitales y cerca de 200 documentos de exposiciones nacionales e internacionales en las que participó, además de gran cantidad de recuerdos de amigos y compañeros.

Para poder exhibirlo se tuvo que tener conocimiento de la totalidad de la obra y luego clasificar y poner en valor las 700 fotografías seleccionadas. Esta tarea le Ilevó al equipo del MAMBA más de cinco meses de trabajo dentro del estudio de Sessa. Teniendo en cuenta su disposición, se organizaron los ocho núcleos temáticos, a través de los cuales la curadora pretende construir una totalidad en la que se incluyan las etapas del fotógrafo, popularmente conocido por sus fotografías en blanco y negro de la ciudad de Buenos Aires.

El artista propuso que se seleccionara un único tema y que se trabajara con las fotografías que respondieran al mismo; sin embargo, la propuesta de Noorthoon era conjugar la totalidad de su archivo personal y hacerlo hablar. Así surgieron los núcleos temáticos diagramados por la escenógrafa brasileña Daniela Thomas. Estos se superponen cronológicamente porque, a veces, los tiempos del archivo no son precisamente los de la historia. Según Andrea Giunta (2010), «los documentos pueden ser elocuentes incluso en su orden original, en esa secuencia con que inducen a pensar que se exponen como un fragmento literal de la historia» (p. 27).

Los núcleos temáticos construidos para la muestra son: «La vieja Buenos Aires (1958-2001)», «Fotoperiodismo (1969-2007)», «Teatro Colón (1982-1987)», «Retratos (1957-2017)», «Nueva York (1962-2017)», «Nueva York (1962-2017)»,
1 Aldo Sessa (Buenos Aires, 1939) inició su formación en las artes gráficas en la imprenta de su padre. Con 17 años realizó sus primeras colaboraciones fotográficas en prensa en el diario La Nación y luego en La Gaceto de Tucumán. Su primer contrato como artista lo firmó en 1972 con la Galería Bonino. A partir de allí, realizó más de 200 exposiciones en el mundo. En 1991 fue nombrado Miembro Honorario de la Federación Argentina de Fotógrafos y Académico de Número de la Academia de Bellas Artes. 
«Viajes (1963-2009)», «Argentina (1980-2010)» y «Naturalezas muertas y abstracciones (1964-2018)».

«La vieja Buenos Aires (1958-2001)» incluye las primeras fotografías de Sessa y, con ellas, su mirada sobre la ciudad cuando comenzó a experimentar con la técnica. «Fotoperiodismo (1969-2007)» es una disciplina en la que se inició como colaborador del diario La Noción y La Gaceto de Tucumán. Las fotos exhiben su particular manera de acercarse al hecho con cámara en mano y sin teleobjetivos, muy cerca de la escena. Así, puso en imágenes sucesos conmovedores de nuestra historia: las marchas de las Madres de Plaza de Mayo, el traslado del féretro de Juan Domingo Perón y las protestas populares ante la crisis de 2001. En «Teatro Colón (1982-1987)» se ven fotografías tomadas sin flash, sin trípode, en la penumbra de los ensayos y funciones. Con su movimiento único, capta la espera de los músicos, el gesto de concentración de los artistas, el instante del bailarín cuando parece volar suspendido en el aire.

Por su parte, en «Retratos (1957-2017)» se muestra la evidencia de una tensión cuerpo a cuerpo en la que el fotógrafo lleva al retratado a componer la escena. «Nueva York (1962-2017)» exhibe formas urbanas a partir de sus reflejos, busca a sus habitantes en sombras tras vidrios opacos y juega con inesperadas situaciones humorísticas. En «Viajes (1963-2009)» hay fotografías de los viajes de Aldo Sessa por Inglaterra, Turquía, Tailandia, La India, China o Birmania. En estas fotos, sessa buscó lo que se conoce como la distancia mínima, en la que el fotógrafo no solo observa, sino que, también, es observado por los ojos que retrata. "Argentina (1980-2010)» presenta un recorrido por las geografías, los biomas y las culturas argentinas. Desde un solitario caserío patagónico y un mar de manzanas en una cosecha rionegrina, con su característica manera de mirar al gaucho. Por último, «Naturalezas muertas y abstracciones (1964-2018)» exhibe fotografías producto de un estudio obsesivo sobre las posibilidades de cada objeto en la privacidad del taller (Aldo Sessa, 2018).

Para la antesala de la muestra [Figura 1] se dispuso, lo que la curadora llama «la contracara del archivo»: los catálogos de muestras, la correspondencia con Manuel Mujica Láinez, Jorge Luis Borges y Silvina Ocampo y, entre otros materiales, algunas cámaras fotográficas. Esta práctica se ha vuelto recurrente en las exhibiciones de artistas contemporáneos. Al mismo tiempo que las paredes de los museos se despojan de textos curatoriales, se colocan revistas y documentos en las vitrinas en una situación intermedia entre el objeto de arte y el documento de archivo (Giunta, 2010). 


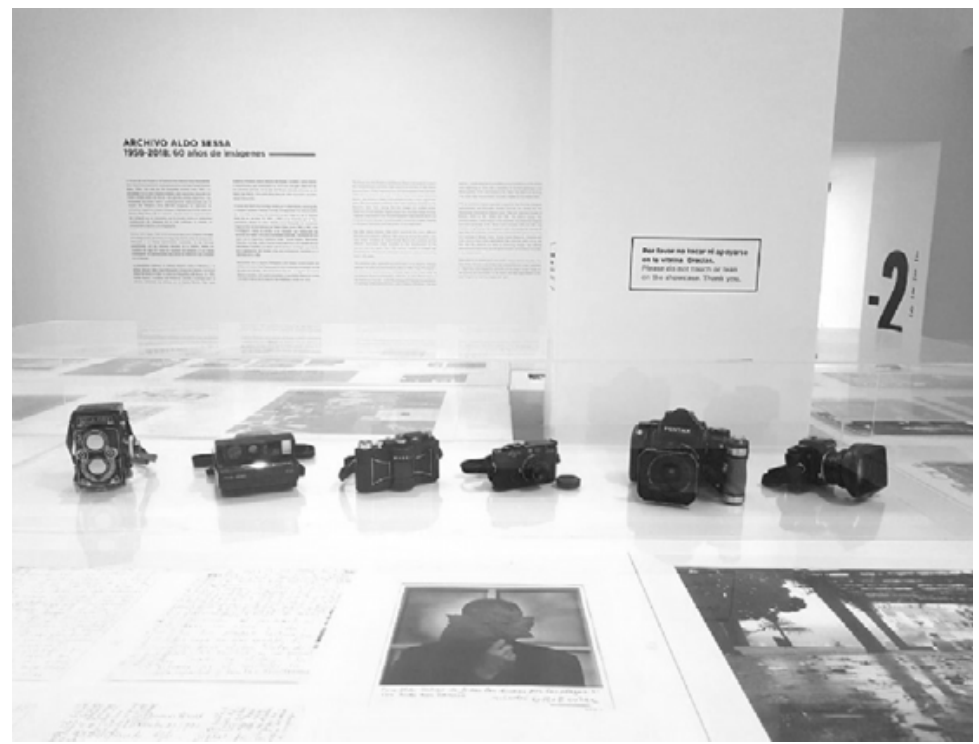

Figura 1. Vista de la exposición Archivo Aldo Sessa 1958-2018: 60 años de fotografías (2018). MAMBA

Para la sala principal, se trató de generar en el espectador la experiencia de sentir una evidencia física. Ante este propósito es que la diseñadora de montaje propuso realizar una línea de horizonte de fotos de veinte centímetros que contaran un relato y desde allí las demás fotografías, de mayor tamaño, se dispondrían cubriendo todo el espacio de los muros, por arriba y por debajo de la línea principal. Así, mientras a la altura de los ojos se trama un relato que pasa, orgánicamente, de los paisajes de Buenos Aires a las bambalinas del teatro, a los retratos, los viajes y las experimentaciones, otros tiempos se abren hacia arriba y hacia abajo de la línea central y crecen para producir intensidades, sinergias y contrapuntos entre las obras [Figura 2]. En este sentido, el archivo transmite su inmensidad cuantitativa a partir de la sensación física que produce ver los muros de la sala completos de obras hasta donde llega la vista. 


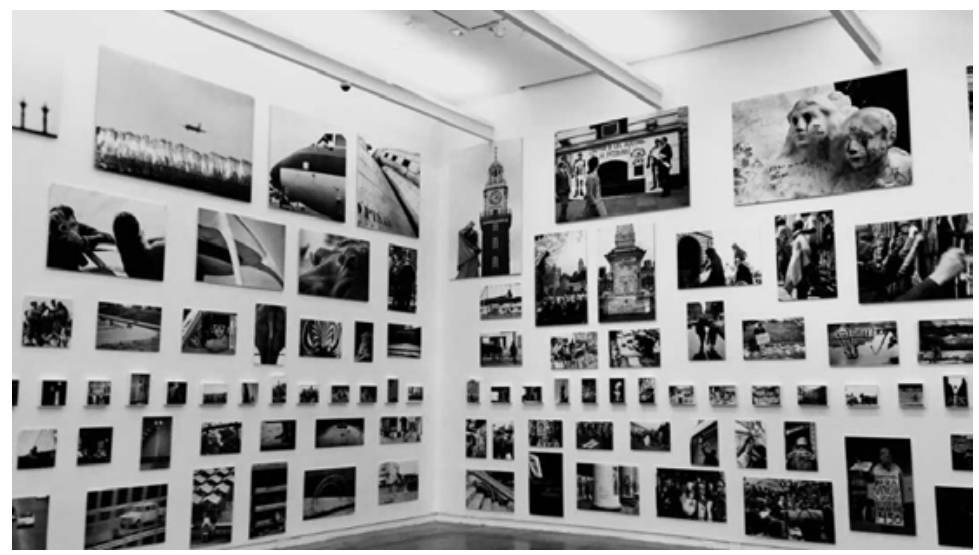

Figura 2. Vista de la exposición Archivo Aldo Sesso 1958-2018: 60 años de fotografías (2018). MAMBA

«Estoy descubriendo a un fotógrafo que desconocía», dijo Aldo Sessa de sí mismo, ante la sorpresa de ver imágenes que hacía tiempo no veía, fotos propias, inéditas, que el artista conservaba en su archivo dentro del estudio donde trabaja (Aldo Sessa, 2018). En esta frase concluyente se condensa la importancia y trascendencia del archivo aún para el propio artista. La activación del mismo posibilitó distinguir diferentes relaciones entre las imágenes, contar otras historias y experimentar nuevas formas de representación del tiempo y del espacio, tanto en su sentido histórico como expositivo.

\section{REFERENCIAS}

Sessa, A. (12 de marzo de 2018). Aldo Sessa: cómo es la gran muestra que celebra sus 6 décadas con la fotografía. Infobae. Recuperado de https://www. infobae.com/cultura/2018/03/12/aldo-sessa-como-es-la-gran-muestra-quecelebra-sus-6-decadas-con-la-fotografia/

Foucault, M. (1979). La arqueología del saber. Ciudad de México, México: Siglo XXI.

Foster, H. (2016). El impulso de archivo. NIMIO. Revisto de la cátedra Teoría de lo Historia, 3(3), 102-125. Recuperado de http://papelcosido.fba.unlp.edu.ar/ojs/ index.php/nimio/article/view/351/586 
Giunta, A. (2010). Archivos. Políticas del conocimiento en el arte de América Latina. Revisto Erroto. Arte y archivos, (1), 20-37. Recuperado de http:// revistaerrata.gov.co/edicion/errata1-arte-y-archivos

Guasch, A. M. (2011). Arte y Archivo, 1920-2010. Geneologías, tipologías y discontinuidades. Madrid, España: Akal.

Museo de Arte Moderno de Buenos Aires (2018). Archivo Aldo Sessa 1958-2018: 60 oños de fotografías [Muestra]. Recuperado de https://www.museomoderno. org/es/exposiciones/archivo-aldo-sessa-1958-2018-60-anos-de-imagenes 